\title{
Study of Surface Tension Properties looked on Contact Angle Value on $100 \%$ Nylon Textile Fabric Using Corona Discharge Plasma Technology
}

\author{
Valentinus Galih Vidia Putra ${ }^{1}$, Juliany Ningsih Mohamad ${ }^{2}$, Yusril Yusuf ${ }^{3}$ \\ ${ }^{1}$ Textile Engineering Department, Politeknik STTT Bandung, Bandung, Indonesia \\ ${ }^{2}$ Physics Department, Universitas Nusa Cendana, Kupang, Indonesia \\ ${ }^{2}$ Physics Department, Universitas Gadjah Mada,Yogyakarta, Indonesia \\ * Penulis Penanggungjawab. E-mail: valentinus@ kemenperin.go.id \\ Telp: $+62-22-7272580$
}

\begin{abstract}
ABSTRAK
Artikel ini menjabarkan pemanfaatan aplikasi teknologi plasma pijar korona pada bidang tekstil dalam modifikasi sifat pembasahan pada permukaan kain nilon 100\% ditinjau dari sifat fenomena kapilaritas. Hasil riset memperlihatkan bahwa dengan perlakuan plasma pada kain nilon 100\% dengan tetal pakan dan lusi masing-masing 70 helai/inci dan 60 helai/inci didapatkan bahwa terdapat perubahan sifat hidrofilik (dapat lebih mudah menyerap) kain melalui perubahan sudut kontak pada fenomena kapilaritas untuk waktu uji sudut kontak yang sama.
\end{abstract}

Kata Kunci : plasma, tekstil, sudut kontak

\section{Abstract}

This paper provides an explanation of the application of corona discharge plasma in textile field specially for modification of surface properties and wet ability of nylon $100 \%$ fabric. In this research, we have found that the properties of wet ability of nylon $100 \%$ fabric with $70 /$ inch of weft density and 60/inch of warp density is influenced by corona discharged plasma analyzed by the contact angle of the fabric on capillarity phenomena under same test time for contact angle test.

Keywords : plasma, textile, contact angle 


\section{Pendahuluan}

Pada bidang tekstil penerapan ilmu fisika telah banyak diimplementasikan oleh banyak peneliti baik secara teori maupun secara eksperimen [1-12]. Rauscher, Perucca, Buyle, [6], Sjaifudin,Widodo,, Muhlisin, Z., Nur. [5], Putra, Maruto dan Rosyid [9] dan Putra, Dewanto, Totong [8] menerapkan ilmu fisika untuk penerapan pada bidang tekstil baik pada ranah pemodelan di pemintalan hingga ranah penerapan praktis pada penyempurnaan kain.

Sebuah perlakuan plasma pada suatu substrat dapat mempengaruhi substrat tersebut yang bergantung pada jenis sumber plasma dan juga gas yang digunakan. Beberapa efek tersebut adalah: surface activation, etching, cross-linking/ polimerisasi dan coating deposition [1]. Surface activation dengan plasma dapat dihubungkan dengan proses chemical grafting atau pencakokan zat kimia.

Proses ini tidak dapat terjadi secara mandiri, tetapi selalu terjadi selama dan setelah proses perlakuan plasma, sebagai contoh pada kasus sebuah substrat yang dikenai perlakuan plasma dengan spesies reaktif seperti $\mathrm{O}_{2}$ atau $\mathrm{CO}_{2}$, maka efek pencakokan zat kimia yang terjadi menjadi dua kali lipat. Atom-atom oksigen akan berinteraksi dengan atom-atom pada substrat (organic contamination), umumnya atom-atom ini dapat berupa ikatan hidrokarbon. Baik $\mathrm{H}$ dan $\mathrm{C}$ akan bereaksi dengan oksigen dan akan meninggalkan permukaan substrat dalam bentuk uap $\mathrm{H}_{2} \mathrm{O}$ dan $\mathrm{CO}_{2}$. Setelah permukaan substrat dari polimer terbebas dari organic contamination, maka molekul-molekul permukaan polimer substrat bereaksi dengan atom oksigen yang akan membentuk gugus fungsi carbonyl-, carboxyl- atau hydroxyl pada substrat [1].

Efek pencakokan (grafting) gugus fungsi tersebut pada permukaan (PP), polietelen (PE) atau polyester seperti polyethyleneterephthalate (PET) dan polybutyleneterephthalate (PBT) akan meningkatkan tingkat energi permukaan secara langsung setelah perlakuan plasma yang akan mengakibatkan naiknya sifat hidrofilik. Efek peningkatan energi permukaan ini tidak permanen, namun memiliki durasi waktu yang cukup lama.

Menurut Shishoo [1] efek pencakokan (grafting) akan membentuk gugus fungsi carbonyl-, carboxyl- atau hydroxyl pada PP, polyethylene (PE), atau polyester seperti PET dan PBT serta memberikan peningkatan energi permukaan hingga lebih dari $68 \mathrm{mN} / \mathrm{m}$ secara langsung setelah perlakuan plasma. Perlakuan plasma pada proses surface activation mengakibatkan adanya peningkatan sifat hidrofilik yang bergantung pada besar energi permukaan dan sudut kontak. 
Menurut Rauscher, Perucca, Buyle [6], sudut kontak dan energi permukaan substrat akan terpengaruh pada perlakuan plasma. Tegangan permukaan padatan dan gas, $\gamma_{S V}$ dapat digunakan sebagai indikator energi permukaan, $U$, material. Energi permukaan adalah suatu ukuran potensi perubahan permukaan suatu padatan terhadap keadaan energi yang lebih rendah dikarenakan adanya susunan dengan fase lain.

Umumnnya semakin kecil sudut kontak $\theta \leq 90^{\circ}$ menunjukan derajat pembasahan yang semakin besar dengan nilai kondisi absorbsi/ imbibition membesar dan akan mengakibatkan energi permukaan dan juga tegangan permukaan padatan $\gamma_{S V}$ meningkat. Tipe gas juga mempengaruhi sudut kontak dan energi permukaan. Gas seperti Ar dan He tidak secara langsung mengubah struktur kimia, sementara gas seperti $\mathrm{O}_{2}$ akan mempengaruhi pengurangan massa dan akan memodifikasi permukaan secara kimia. Umumnya penggunaan $\mathrm{O}_{2}$ biasa digunakan untuk dekontaminasi permukaan (menghilangkan polutan mikro organic dari permukaan), menambah sifat basah (wettability) serta sifat adesif pada perlakuan akhir.

Pada penelitian ini pemanfaatan aplikasi teknologi plasma pijar korona pada bidang tekstil dalam modifikasi sifat pembasahan pada permukaan kain nilon $100 \%$ ditinjau dari sifat fenomena kapilaritas akan dikaji untuk dapat memperlihatkan bahwa dengan perlakuan plasma pada kain nilon $100 \%$ dengan tetal pakan dan lusi masing-masing 70 helai/inci dan 60 helai/inci didapatkan bahwa terdapat perubahan sifat hidrofilik kain melalui perubahan sudut kontak pada fenomena kapilaritas untuk waktu perlakuan yang berbeda.

\section{Metode}

Rancangan percobaan dan peralatan dalam penelitian ini dapat diperlihatkan pada Gambar 1. Reaktor plasma korona dengan tiga buah elektroda lancip dan sebuah silinder pejal yang terbuat dari lempengan logam. Elektroda titik yang digunakan berupa baut runcing (lancip) dan berjumlah tiga buah yang dipasangkan pada suatu papan yang terhubung seri dengan jarak 1,5 cm tiap bautnya.

Elektroda titik digunakan sebagai elektroda positif (anoda yang terhubung ke tegangan sumber) dan dan dipasang tegak lurus terhadap elektroda silinder pejal sebagai elektroda negatif (katoda yang terhubung ke ground). Jarak antara elektroda positif dan elektroda silinder pejal adalah 2,5 cm. Bahan kain tekstil berupa kain nilon $100 \%$ berukuran 10x6 $\mathrm{cm}^{2}$, ketebalan $0,2 \mathrm{~mm}$, digunakan sebagai sampel diletakkan di atas elektroda negatif silinder pejal. Plasma pijar korona dibangkitkan menggunakan 
sumber tegangan tinggi DC $3 \mathrm{kV}$. Nilai tegangan diukur menggunakan multimeter tegangan tinggi dan penentuan kondisi lingkungan adalah pada tekanan atmosfer dengan suhu ruangan $27^{\circ} \mathrm{C}-28^{\circ} \mathrm{C}$ yang diukur menggunakan thermometer gun dengan medium gas ruangan $\left(\mathrm{O}_{2}\right)$.

Kain nilon diletakkan pada pada elektroda silinder pejal dan dilakukan modifikasi permukaan kain menggunakan perlakuan plasma pijar selama beberapa waktu yaitu 10 detik, 30 detik dan 60 detik dengan tegangan DC $3 \mathrm{kV}$. Kain nilon yang digunakan adalah kain nilon dengan tetal benang lusi adalah 60 helai/inch dan tetal benang pakan 70 helai/inch. Kain nilon yang telah dimodifikasi permukaan menggunakan plasma dilakukan uji sudut kontak selama waktu serap yang sama (dalam hal ini dipilih waktu uji sudut kontak selama 10 detik) sesaat kain nilon diradiasi menggunakan generator plasma.

Uji sudut kontak dengan menggunakan tetes dilakukan menggunakan piranti kamera dan juga software image processing di Laboratorium Mekatronika Politeknik STTT Bandung untuk mengukur sudut kontak dengan cairan tetes berupa air murni untuk melakukan pengukuran sudut kontak. Pembangkitan plasma pada generator plasma tak simetri dapat diatur secara visual melalui pengaturan tegangan input AC dan tegangan output DC.

Untuk analisa pergerakan elektron dapat digunakan multimeter tegangan tinggi yangmana arah pergerakan elektron akan berlawanan dengan arah pergerakan arus dan medan listrik statik E. Pada keadaan tegangan listrik plasma (ditandai dengan munculnya cahaya biru pada daerah elektroda positif baut lancip (Gambar 1) dapat diperlihatkan munculnya muatan ion-ion positif (berwarna ungu kebiruan) yang bersumber dari tegangan positif yang berlawanan dengan arah gerak elektron.
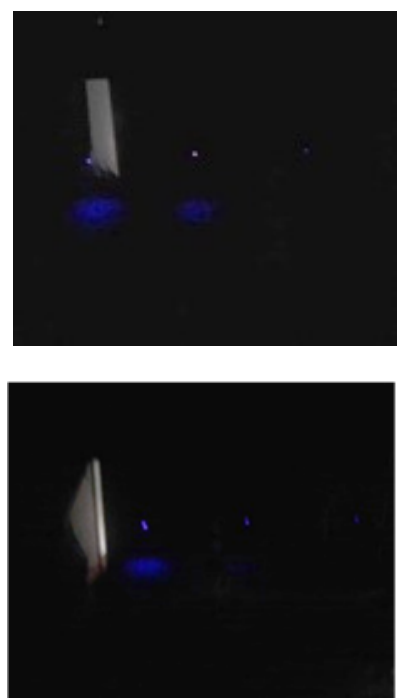

Gambar 1. Generator Plasma Pijar Korona

Muatan yang bergerak ini diawali oleh peristiwa ionisasi yang berada pada elektroda tiga titik dan dibangkitkan dari tegangan tinggi anoda. Ionisasi terjadi pada daerah elektroda positif, karena pengaruh suatu medan listrik statik $E$ dengan intensitas tinggi yang dibangkitkan dengan tegangan tinggi (High Voltage). Ion hasil ionisasi pada zona ionisasi (zona plasma) di daerah baut lancip atau anoda bergerak menuju elektroda negatif silinder pejal (katoda) 
melalui suatu daerah drift region. Aliran ion-ion ini akan menimbulkan arus ion yang disebut arus saturasi unipolar. Aliran ion positif tersebut membawa molekul dan juga atom gas pada daerah antara elektroda baut dan silinder pejal tersebut. Aliran ion positif ini bergerak menuju permukaan kain nilon dan menumbuk permukaan kain nilon sehingga dapat memodifikasi sifat kekasaran kain.

\section{Hasil dan Pembahasan}

Menurut Rauscher, Perucca, Buyle [6], sudut kontak dan energi permukaan substrat akan terpengaruh pada perlakuan plasma. Energi permukaan adalah suatu ukuran potensi perubahan permukaan suatu padatan terhadap keadaan energi yang lebih rendah dikarenakan adanya susunan dengan fase lain.

Umumnnya semakin kecil sudut kontak

$$
\theta \leq 90^{\circ}
$$

menunjukan derajat pembasahan yang semakin besar dengan nilai kondisi absorbsi/ imbibition membesar dan akan mengakibatkan energi permukaan dan juga tegangan permukaan padatan

\section{$\gamma_{S V}$ meningkat.}

Tipe gas juga mempengaruhi sudut kontak dan energi permukaan gas, seperti $\mathrm{O}_{2}$ akan mempengaruhi pengurangan massa dan akan memodifikasi permukaan secara kimia.
Umumnya penggunaan $\mathrm{O}_{2}$ biasa digunakan untuk dekontaminasi permukaan (menghilangkan polutan mikro organik dari permukaan), menambah sifat basah (wettability) serta sifat adesif pada perlakuan akhir.

Uji tetes air dilaksanakan pada sampel kain nilon berukuran 10x6 $\mathrm{cm}^{2}$, ketebalan 0,2 $\mathrm{mm}$ untuk modifikasi permukaan kain nilon melalui perlakuan plasma selama 10 detik, 30 detik dan 60 detik dengan tegangan DC $3 \mathrm{kV}$ serta gas ruangan sebagai media plasma. Pengujian langsung dilakukan setelah selesainya proses modifikasi permukaan kain menggunakan plasma dengan pengukuran sudut kontak dan uji tetes dengan pipet.

Hasil pengujian sudut kontak sesudah modifikasi permukaan dengan plasma kemudian dibandingkan dengan sudut kontak serap kain nilon sebelum perlakuan plasma. Hasil uji sudut kontak dapat diperlihatkan pada Gambar 2.

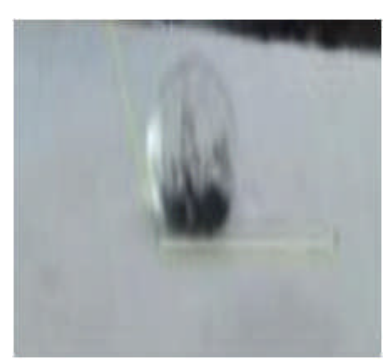

(a)

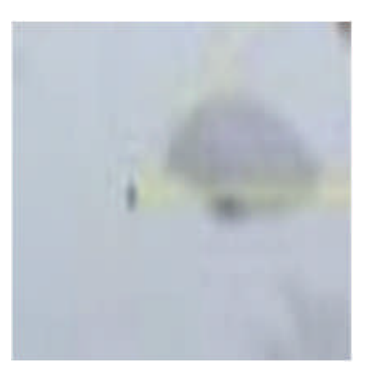

(b)
Gambar 2. Hasil uji sudut kontak pada kain. (a) sebelum plasma untuk waktu ukur 10 detik, (b) sesudah pemaparan radiasi plasma selama 60 detik untuk waktu ukur 10 detik 
Rauscher, Perucca, Buyle [6] menyatakan bahwa salah satu cara untuk menentukan besarnya tegangan permukaan adalah dengan menentukan besarnya sudut kontak $\theta$ antara suatu cairan (droplet) pada suatu benda padat waktu yang sama. Pada tetesan air tersebut akan terjadi tiga tegangan, yaitu tegangan permukaan/ tegangan antarmuka liquid-vapour

$\gamma_{L V}$, tegangan antarmuka solid-vapor

$\gamma_{S V}$ dan tegangan antarmuka solidliquid $\gamma_{S L}$. Ketiga gaya tersebut bekerja sesuai dengan skema tetesan air seperti pada Gambar 3 berikut.

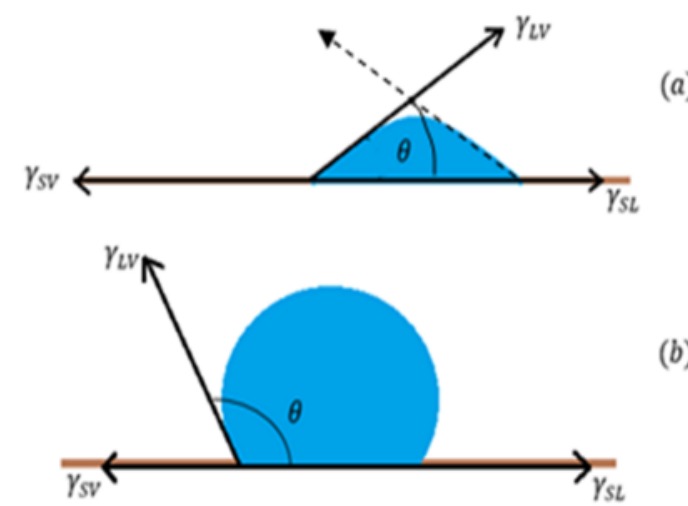

Gambar 3. Uji sudut kontak a) kondisi hidrofilik dan b) kondisi hidrofobik

Beberapa peneliti [1], [4], [5] dan [6] menjelaskan hubungan antara besarnya sudut kontak $\theta$ pada tetesan (water droplet) terhadap sifat pembasahan (wetting). Sudut kontak $\theta$ yang semakin kecil menunjukan derajat pembasahan yang semakin besar dengan nilai kondisi absorbsi/ imbibition membesar sehingga mengakibatkan modifikasi permukaan substrat menjadi hidrofilik. Besar gaya resultan pada daerah kontak dapat dituliskan seperti pada persamaan (1) hingga persamaan (5) di bawah

$$
\begin{aligned}
& \sum F_{x}=0 \\
& \sum \gamma_{x} l=0 \\
& \sum \gamma_{x}=0
\end{aligned}
$$

$$
\begin{gathered}
\gamma_{S L}+\gamma_{L V} \cos \theta-\gamma_{S v}=0 \\
\gamma_{S L}+\gamma_{L V} \cos \theta=\gamma_{S v}
\end{gathered}
$$

Berdasarkan ekspeimen uji sudut kontak untuk kain nilon dengan pemaparan radiasi selama 10 detik, 30 detik dan 60 detik didapatkan besar sudut kontak seperti pada Tabel 1 di bawah ini.

Tabel 1. parameter sudut kontak untuk kasus lama waktu uji sudut kontak 10 detik dan misal $\gamma_{L v}=1$

\begin{tabular}{ccc}
\hline $\begin{array}{c}\text { Sudut } \\
\text { kontak } \\
\theta\end{array}$ & $\begin{array}{c}\text { Waktu } \\
\text { pemaparan } \\
\text { plasma }\end{array}$ & $\begin{array}{c}\text { absorbsi/ } \\
\text { imbibitions }\end{array}$ \\
\hline $108^{\circ}$ & 0 & -0.309 \\
\hline $35^{\circ}$ & 10 detik & 0.819 \\
\hline $28^{\circ}$ & 30 detik & 0.88 \\
\hline $0^{\circ}$ & 60 detik & 1 \\
\hline
\end{tabular}


Berdasarkan hasil eksperimen didapatkan bahwa besar sudut kontak sebelum dan sesudah perlakuan pemaparan radiasi plasma mengalami perbedaan yang cukup besar. Pada pemaparan radiasi plasma selama 10 detik mengakibatkan sudut kontak $\theta=35^{\circ}$ selama waktu uji sudut kontak 10 detik. Pada pemaparan radiasi plasma selama 30 detik mengakibatkan sudut kontak $\theta=28^{\circ}$ dan sudut kontak akan minimal saat pemaparan 60 detik selama waktu uji sudut kontak 10 detik. Besar nilai sudut kontak memiliki suatu hubungan dengan suatu nilai absorbsi untuk pemisalan nilai $\gamma_{L v}=1$, yaitu semakin besar sudut kontak pada suatu substrat, maka semakin kecil nilai absorbsi material, dengan besar nilai absorbsi maksimal berada pada waktu pemaparan selama 60 detik.

Menurut Rauscher, Perucca, Buyle [6], sudut kontak dan energi permukaan substrat akan terpengaruh pada lama waktu perlakuan plasma. Energi permukaan adalah suatu ukuran potensi perubahan permukaan suatu padatan terhadap keadaan energi yang lebih rendah dikarenakan adanya susunan dengan fase lain. Umumnnya semakin kecil sudut kontak $\theta \leq 90^{\circ}$ menunjukan derajat pembasahan yang semakin besar dengan nilai kondisi absorbsi/ imbibition membesar dan akan mengakibatkan energi permukaan dan juga tegangan permukaan padatan $\gamma_{S V}$ meningkat.
Berdasarkan hasil eksperimen serta teori maka pada penelitian ini kenaikan daya serap kain nilon sebelum dan sesudah perlakuan plasma dapat ditimbulkan oleh adanya tumbukan yang besar dari radiasi plasma pada permukaan kain nilon (ditandai dengan adanya pergerakan ion ke permukaan kain yang secara visual tampak sebagai cahaya ungu kebiruan), sehingga mengakibatkan hilangnya massa dan putusnya rantai polimer.

Semakin lama waktu pemaparan kain nilon, maka semakin kecil sudut kontak yang mengakibatkan besar nilai absorbsi semakin besar. Pada penelitian ini perlakuan paparan plasma mengakibatkan perubahan sifat daya serap kain menjadi material hidrofilik yang bergantung pada lama waktu pemaparan radisi plasma. Semakin lama waktu pemaparan maka akan semakin hidrofilik suatu material tekstil.

\section{Simpulan}

Hasil riset memperlihatkan bahwa dengan melakukan variasi waktu perlakuan plasma pada kain nilon dengan tetal pakan dan lusi masing-masing 70 helai/inci dan 60 helai/inci didapatkan bahwa terdapat perubahan sifat pembasahan kain dengan meningkatnya sifat hidrofilik kain yang ditandai dengan mengecilnya besar sudut kontak. 


\section{Ucapan Terima Kasih}

Terimakasih kepada pihak pemberi dana penelitian Politeknik STTT Bandung dan kepada para kolega yang membantu penelitian serta diskusi.

\section{Referensi}

1. Shishoo (2007), Plasma Technology For Textile, Woodhead Publishing, Cambridge.

2. Usman, A.S. (2012). Peningkatan Daya Saing Industri TPT Melalui Standarisasi, Makalah Seminar Nasional Tekstil, Bandung.

3. Yales, V. Kendalikan Konsumsi Energi Sektor Manufaktur. Surat Kabar KOMPAS, 18 April 2012, halaman 7

4. Kaiser, M., Baumgartner, K.-M., Schulz, A., Walker, M., and Rauchle, E. (1999) Linearly extended plasma source for largescale applications. Surf. Coat. Technol., 116-119, 552-557

5. Sjaifudin T.A.,Widodo, M., Muhlisin, Z., Nur, M. (2014). Modifikasi Permukaan Bahan Tekstil Dengan Plasma Lucutan Korona, Prosiding Seminar Nasional Tekstil, 1-22.

6. Rauscher, Perucca, Buyle (2010), Plasma Technology For Hyperfunctionals Surfaces, Wiley -VCH, Weinheim.
7. Lawrence, C A (2003), Fundamentals of Spun Yarn Technology, CRC Press, New York

8. Putra VGV, Dewanto A, Totong, (2016), Predicting Non Inertia Frame Related By Speed of Bobbin Compared by Speed of Rotor, Global Journal of Pure and Applied Mathematics, Vol 12.,No.5 pp. 4107-4114.

9. Putra VGV, Maruto, G \& Rosyid, M.F. (2017), New theoretical modeling for predicting yarn angle on OE yarn influenced by fibre movement on torus coordinate based on classical mechanics approach, Indian Journal of Fibre and Textile Research, Vol.42. pp. 359-363.

10. F. F. Chen, (1984), Introduction to Plasma Physics and Controlled Fusion, vol. 1, New York: Plenum Press.

11. Lieberman, M \& Lichtenberg, (1994), Principles of Plasma Discharges and Materials Processing, New York: John Wiley and Sons.

12. Putra, V. G. V., Wijayono, A., Martina, T., \& Rosyidan, C. (2019). SUATU STUDI PEMODELAN VISKOELASTIK MATERIAL BENANG VIZ 100\% WOOL 36 TEX MENGGUNAKAN PENDEKATAN FISIKA. Wahana Fisi$k a, 4(1), 27-34$. 